\title{
McQuaid-Ehn Grain Size Determined By Spectrochemical Analysis
}

\author{
by G. E. Ressler
}

\begin{abstract}
A USTENITIC grain size is controlled primarily by the addition of aluminum under proper slag and molten metal conditions. The Timken Roller Bearing Co. has found that a range of 0.015 to 0.035 pct metallic aluminum produces a fine-grained killed steel in the carburizing and medium carbon grades.

Wet chemical methods for aluminum determinations have been useful for some time in standardizing melting practices to achieve grain size control. However, when the analysis of a large number of heats is necessary, wet chemical determinations are not practical because of the cost and time required. With the advent of the spectrochemical method of obtaining chemical analysis and the subsequent development of the direct reading spectrometer, it is now economical to make numerous aluminum determinations.
\end{abstract}

\section{Correlated Data}

The spectrochemical method reports the metallic aluminum together with the aluminum present as an oxide. Numerous wet chemical determinations have shown that the $\mathrm{Al}_{2} \mathrm{O}_{3}$ content runs consistently between 0.006 to 0.010 pct in the fine-grained aluminum steels. This percentage of $\mathrm{Al}_{2} \mathrm{O}_{3}$ represents 0.003 to 0.005 pet aluminum present as an oxide. Since this amount of the aluminum is in the oxide form it is not effective in controlling grain size.

Timken's experience has shown that when 0.015 pct minimum spectrochemical aluminum is retained with standard addition and deoxidation practice, the aluminum present as an oxide is a constant factor of 0.003 to 0.005 pct. The factor of 0.003 to 0.005 pct can thus be used in correcting the spectrochemical results to effective metallic aluminum content. If an excessive amount of $\mathrm{Al}_{2} \mathrm{O}_{3}$ is formed because of improper furnace conditions, the expected aluminum

G. E. RESSLER is Assistant Mill Metallurgist, Steel \& Tube Div., Timken Roller Bearing Co., Canton, Ohio. This article is an abstract of the paper presented at the AIME Electric Furnace Steel Conference, Cincinnati, Dec. 2-4, 1953. recovery either as an oxide or in the desired metallic form is not obtained.

Late in 1949, spectrochemical aluminum analysis were run on both early and late ladle tests. The first extensive study included 961 electric furnace heats of TS 4720 steel and other higher alloy grades of carburizing steels melted for the Timken roller bearing factory. The relationship between spectrochemical aluminum determinations and McQuaid-Ehn grain size is shown in Table I. This data points up the following:

A-All 881 heats finished 0.016 pet aluminum or higher, and 879 , or 99.8 pct, are No. 6 gr size or finer while all 881 heats are No. 5 gr size or finer.

$\mathrm{B}$ - In the aluminum range 0.011 to $0.015 \mathrm{pct}$, the grain size still remains fine with a trend to the coarser side of the fine-grain range.

$\mathrm{C}$-In the aluminum range 0.006 to $0.010 \mathrm{pct}$, the grain coarsening is pronounced at $1700^{\circ} \mathrm{F}$.

$\mathrm{D}$-In the aluminum range 0.000 to 0.005 pct, all the heats coarsen at $1700^{\circ} \mathrm{F}$.

On the basis of this convincing evidence, that fine-grained steel is assured by a minimum of 0.016 pct spectrochemical aluminum content, the Timken roller bearing factory consented to accept spectrochemical determinations as the yardstick for measuring grain size in its steel. At present, in the roller bearing factory grades, micro-inspection on carburized tests are made only when the aluminum content is outside the recommended aluminum content range. However, additional data on heats with 0.012 to 0.016 pet aluminum has shown that in type TS 4720 steel coarse grain steel does not occur down to 0.012 pet aluminum.

Early in 1953, spectrochemical aluminum determinations on over 2000 heats had been acculmulated with continued verification of previous results. A number of Timken customers were approached on using spectrochemical aluminum determinations for the release of fine-grained steels. As a consequence fine-grained steels are now released to Timken customers on the basis of spectrochemical aluminum analysis with satisfactory results.

Table I. Relationship of Spectrochemical Aluminum to McQuaid-Ehn Grain Size

\begin{tabular}{|c|c|c|c|c|c|c|c|c|c|}
\hline \multirow[b]{2}{*}{ McQuaid-Ehn grain size } & \multicolumn{6}{|c|}{ Fine Grain Size } & \multicolumn{3}{|c|}{ Coarse Grain Size } \\
\hline & 8 & $7 / 8$ & $6 / 8$ & $6 / 7$ & $5 / 8$ & $5 / 7$ & $4 / 7$ & $3 / 7$ & $3 / 6$ \\
\hline Number of heats & 537 & 277 & 133 & 5 & 2 & 1 & 2 & 1 & 3 \\
\hline Aluminum, Pct & \multicolumn{9}{|c|}{ Percentage of Heats } \\
\hline $0.000-0.005$ & - & - & - & - & - & - & - & - & 66.7 \\
\hline $0.006-0.010$ & 0.2 & 0.7 & 4.5 & 20.0 & - & 100.0 & 100.0 & 100.0 & $\begin{array}{l}00.8 \\
33.3\end{array}$ \\
\hline $0.011-0.015$ & 2.8 & 7.6 & 18.0 & 40.0 & - & - & - & - & - \\
\hline $0.016-0.035$ & 83.6 & 75.1 & 64.0 & 40.0 & 100.0 & - & - & - & - \\
\hline $0.036-0.040$ & 8.4 & 8.3 & 8.3 & - & - & - & - & $=$ & - \\
\hline $0.041-0.045$ & 3.2 & 3.6 & 2.3 & - & - & - & - & - & 二 \\
\hline $0.046-0.060$ & 1.8 & 4.7 & 2.9 & - & - & - & - & - & - \\
\hline
\end{tabular}

